\title{
Spectral Analysis of Hourly Solar Radiation
}

\author{
Vasilios Ambas • Evangelos Baltas
}

Received: 7 February 2014 / Accepted: 6 May 2014 / Published online: 11 June 2014

(C) Springer International Publishing Switzerland 2014

\begin{abstract}
This research aims at the precise estimation of solar radiation, on an hourly and daily basis, by using measured data of solar radiation and sunshine duration. Data is collected from the automatic meteorological station of Amynteo, West Macedonia, Greece. For the correlation of solar radiation and sunshine duration, the Angström-Prescott equation is selected. Two limit conditions of cloud coverage are examined, overcast and clear sky, for the estimation of the factors $a_{s}$ and $b_{s}$ of the Angström-Prescott equation. The factor $a_{s}$ is the minimum transmissivity for overcast sky, while $a_{s}+b_{s}$ is expressing the clear sky transmissivity. In addition, spectral analysis is performed to investigate the periodicities of the factors $\mathrm{a}_{\mathrm{s}}$ and $b_{s}$. The Lomb-Scargle periodogram is applied, as data are unevenly distributed in time, and reveals the existence of two periodicities for the $b_{s}$ factor. More specifically, annual periodicity with an estimated width equal to 0.032 , and daily periodicity with a width equal to 0.184 . As a result of this research, a sinusoidal equation with two harmonics is developed to calculate the $b_{s}$ factor, which coincides with the clearness index $\left(R_{s} / R_{a}\right)$ under clear sky. In overcast conditions, the clearness index does not exhibit periodicities. The derived equation is used to produce estimations of solar radiation values on an hourly and daily basis. The daily values estimated from the new equation gives better results when compared to typical regression analysis.
\end{abstract}

Keywords Sunshine $\cdot$ Solar radiation $\cdot$ Spectral analysis $\cdot$ Hourly values $\cdot$ Clear sky $\cdot$ Overcast

\section{Introduction}

Solar radiation Rs, also known as global radiation, is the portion of the extraterrestrial radiation that reaches the earth's surface. Solar radiation is the sum of direct shortwave radiation of the sun and diffused radiation. The rest of the extraterrestrial radiation is scattered, reflected or absorbed by the atmospheric gases, clouds and air dust as it enters the atmosphere.

\footnotetext{
V. Ambas

Department of Soil-Water Resources Conservation, Region of Western Macedonia, Ptolemeon 1, 53100 Florina, Greece

e-mail: ambasv@gmail.com

E. Baltas $(\bowtie)$

Department of Water Resources, School of Civil Engineering, National Technical University of Athens, 15780 Zografou, Greece

e-mail: baltas@chi.civil.ntua.gr
} 
Knowledge of regional solar radiation data is essential for many applications, such as:

- The design of solar energy systems

- The design of irrigation systems with the use of evapotranspiration models

- The application of hydrological models

- Architectural design

- The application of models that simulate crop growth, because growth is primarily based on the photosynthetic processes, which involves the utilization of radiation and its conversion to chemical energy

Several empirical models have been developed to calculate global solar radiation using various common parameters. These parameters include: extraterrestrial radiation, sunshine duration hours, mean temperature, maximum temperature, soil temperature, relative humidity, number of rainy days, altitude, latitude, total precipitable water, albedo, cloudiness and evaporation. Models, for the estimation of solar radiation, can be grouped in the following categories:

1. Linear models regarding relative sunshine, divided in:

a) Annual models

b) Monthly models

c) Daily models

d) Models with additional topographical parameters

e) Models with additional meteorological parameters

2. Non-linear models regarding relative sunshine.

Hourly and daily solar radiation from the beginning of the 20th century was calculated by the sunshine, with the use of burning spots on special cards. The sunshine data from these cards can be converted into digital files by using modern technological equipment for their digitization. Yang et al. (2006) gave an empirical quadratic equation for the calculation of hourly solar radiation using the relative sunshine. In a previous work by the authors (Ampas and Baltas 2007), daily values of solar radiation were estimated, taking into account the distribution of sunshine during the day. Also, the estimation of hourly sunshine values was developed by using hourly weighting factors (Ampas and Baltas 2007).

The present work performs spectral analysis on the time series of hourly data of the clearness index. An original sinusoidal equation is developed to estimate the hourly and daily solar radiation based on sunshine data collected hourly.

\section{Measurement of Solar Radiation $\left(\mathbf{R}_{\mathrm{S}}\right)$}

Solar radiation can be measured by pyranometers, radiometers or solarimeters. A pyranometer is an instrument used to measure global radiation. The instrument has a hemispherical view of its surroundings. With the use of two thermal sensors, with one exposed to the solar radiation, and the other shaded, the temperature difference is measured and is used to estimate solar radiation.

Existing research has approached the measurement of solar radiation in various ways. Angström (1924) noticed that solar radiation is a linear function of sunshine; 
later Prescott (1940), modified Angström's equation and provided the following formula:

$$
\frac{\mathrm{R}_{\mathrm{s}}}{R_{a}}=\mathrm{a}_{\mathrm{s}}+\mathrm{b}_{\mathrm{s}} \frac{\mathrm{n}}{\mathrm{N}}
$$

where: $\mathrm{R}_{\mathrm{s}}$ is the solar radiation $\left[\mathrm{MJ} \mathrm{m} \mathrm{may}^{-1}\right.$ ]; $\mathrm{R}_{\mathrm{a}}$ is the extraterrestrial radiation $\left[\mathrm{MJ} \mathrm{m}^{-2}\right.$ day $\left.^{-1}\right] ; \mathrm{R}_{\mathrm{s}} / \mathrm{R}_{\mathrm{a}}$ is the clearness index [-], also denoted with $\mathrm{K}_{\mathrm{T}} ; \mathrm{n}$ is the actual duration of sunshine which represents the hours of the day that the sun is visible in the sky and is also called sunshine duration or simply sunshine. It is defined as the time during the day of direct light intensity above $120 \mathrm{~J} \mathrm{~m}^{-2} \mathrm{~s}^{-1}$. It is usually measured via a Campbell-Stokes sunshine recorder. Additionally, an automatic instrument to measure sunshine is the Foster Sunshine Switch [h]; $\mathrm{N}$ is the maximum possible duration of sunshine or daylight hours $[\mathrm{h}] ; \mathrm{n} / \mathrm{N}$ is relative sunshine duration $[-] ; a_{\mathrm{s}}$ is the minimum transmissivity, a regression constant expressing the fraction of extraterrestrial radiation reaching the earth on overcast days $(n=0)[-]$; $b_{\mathrm{s}}$ is the transmissivity angular coefficient $[-] ;\left(a_{s}+b_{s}\right)$ is expressing the clear sky transmissivity, and is the fraction of extraterrestrial radiation reaching the earth in clear days $(n=\mathrm{N})$.

$R_{a}$ for each day of the year is given by Duffie and Beckman (2006) and Kalogirou (2009) by:

$$
R_{a}=\frac{24(60)}{\pi} G_{s c} d_{r}\left[\omega_{s} \sin (\phi) \sin (\delta)+\cos (\phi) \cos (\delta) \sin \left(\omega_{s}\right)\right]
$$

where: $\mathrm{G}_{\mathrm{sc}}$ is the solar constant $=0.0820\left[\mathrm{MJ} \mathrm{m}^{-2} \mathrm{~min}^{-1}\right] ; \mathrm{d}_{\mathrm{r}}$ is the inverse relative distance Earth-Sun [rad]; $\omega_{\mathrm{s}}$ is the sunset hour angle [rad]; $\phi$ is the latitude [rad]; and $\delta$ is the solar decimation [rad]. $\mathrm{N}$ is given by:

$$
N=\frac{24}{\pi} \omega_{s}
$$

For hourly or shorter time periods the extraterrestrial radiation is described by the following relation:

$$
R_{a}=\frac{12(60)}{\pi} G_{s c} d_{r}\left\{\left(\omega_{2}-\omega_{1}\right) \sin (\phi) \sin (\delta)+\cos (\phi) \cos (\delta)\left(\sin \left(\omega_{2}\right)-\sin \left(\omega_{1}\right)\right)\right\}
$$

where: $\omega_{1}, \omega_{2}$ are the solar time angles at the beginning and at the end of the period, respectively [rad].

Based on the Angström-Prescott equation, many researchers appointed values to the factors $a_{s}$ and $b_{s}$, e.g., Yin et al. (2008), Trnka et al. (2005) and Zekai (2001). Some researchers considered that the linear equation gave better results for monthly values, e.g., Almorox et al. (2005). Klabzuba et al. (1999) presented a relation using the day of the year. Other researchers involved topographical parameters, e.g., Gopinathan (1988). Moreover, other researchers inserted additional meteorological parameters. Some researchers used non-linear equations, e.g., Jin et al. (2005).

\section{Analysis of the Data Used}

Data for the present study was taken from the Automatic Meteorological Station (AMS) located at Amynteo (40 41'40'N, 2040'40'E). The AMS of Amynteo belongs to an AMS network that operates in the Prefecture of Florina, Western Macedonia, Greece. This area is an 
interesting area concerning the rainfall and temperature pattern (Baltas 2007). All AMSs are equipped with various sensors, a data logger, a communication system and a power supply system. The AMS of Amynteo measures temperature, relative humidity, wind speed, wind direction, precipitation, solar radiation, sunshine duration, atmospheric pressure and soil temperature every $10 \mathrm{~s}$. The data logger records data every $5 \mathrm{~min}$. For reasons of data uniformity in the AMS network, the 5-min data are transformed to hourly data. The data collection from the stations is achieved by a UHF radio modem connected to a server. The AMS is power supplied by the main electrical network. Solar Radiation is measured by pyranometers and sunshine is measured by the Foster Sunshine Switch.

\section{Modeling Solar Radiation}

The factors $a_{s}$ and $b_{s}$ of the Angström-Prescott equation, as pointed out by Hinrichsen (1994), must be estimated by their physical meaning: $a_{s}$ represents overcast days and $a_{s}+b_{s}$ represents the clear sky days. More specifically, $a_{\mathrm{s}}$ expresses the diffused radiation and $b_{\mathrm{s}}$ the direct radiation. Ampas (2010), using Glover's diagrams (Glover and McCulloh 1958), explained why the annual values of the factors $a_{s}$ and $b_{s}$ are susceptible to significant error when applied for the discrete situations of overcast and clear sky days. Therefore, hourly data are selected to provide useful information about the relation between sunshine and solar radiation.

\subsection{Clear Sky}

ASCE (2005) proposed an equation for calculating solar radiation in clear sky conditions, taking into account the covered distance of sunlight in the atmosphere, the water content of the atmosphere, air mass and dust. Examined monthly values for clear sky days are presented in Fig. 1.

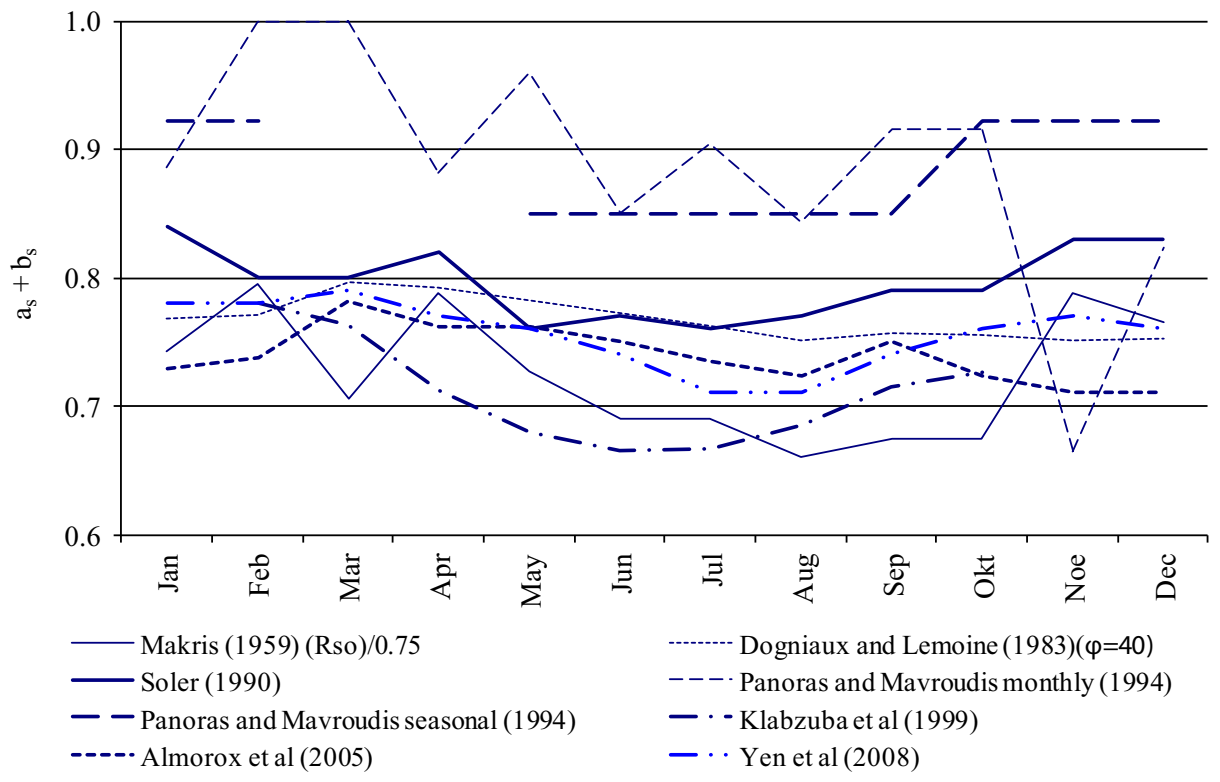

Fig. 1 Clearness index under clear sky conditions as the sum of $a_{s}$ and $b_{s}$ 
Seasonality is the main characteristic of all meteorological parameters. Thus, all equations mentioned above, that incorporate meteorological parameters, cause seasonality to the clearness index. Annual seasonality can also be distinguished in Fig. 1. Existing research shows that curves following uniform annual variations reach the lower value of the clearness index in the summer and the highest in the winter. The annual periodicity of the clearness index under clear sky conditions, $\mathrm{K}_{\mathrm{To}}$, can be seen in Fig. 2, where particularly low values are observed during the summer and high values in the winter.

As the travel distance of sunlight in the atmosphere changes through the day, a daily periodicity of the clearness index takes place. The daily periodicity of the clearness index under clear sky conditions, $\mathrm{K}_{\mathrm{To}}$, can be seen at the hourly values, in Fig. 3.

Spectral analysis was used to determine all the periodicities of time series data of the clearness index under clear sky conditions. Spectral density revealed the way time series data are spread versus frequency because a peak in the periodogram denotes an important frequency. Spectral density was computed by:

$$
S D=\int_{-\infty}^{\infty} x(t) e^{i \omega t} d t
$$

where: $x(t)$ is function of time; $\omega$ is the frequency.

A computer program was developed in programming language $\mathrm{R}$ to estimate the spectrum of the clearness index under clear sky conditions, $\mathrm{K}_{\mathrm{To}}$, and the results are depicted in Fig. 4. Two peaks can be detected in the periodogram of the clearness index under clear sky conditions. The first peak is near the frequency $1 / 4,380$ and denotes the annual periodicity. The second peak is near the frequency $1 / 12$ and denotes the daily periodicity.

Moreover, the Lomb-Scargle method was applied (Broersen 2008), which is a method for analyzing non-uniform data and fit sinusoidal functions to time series data. Data on the clearness index under clear sky conditions, $\mathrm{K}_{\mathrm{To}}$, for spectral analysis

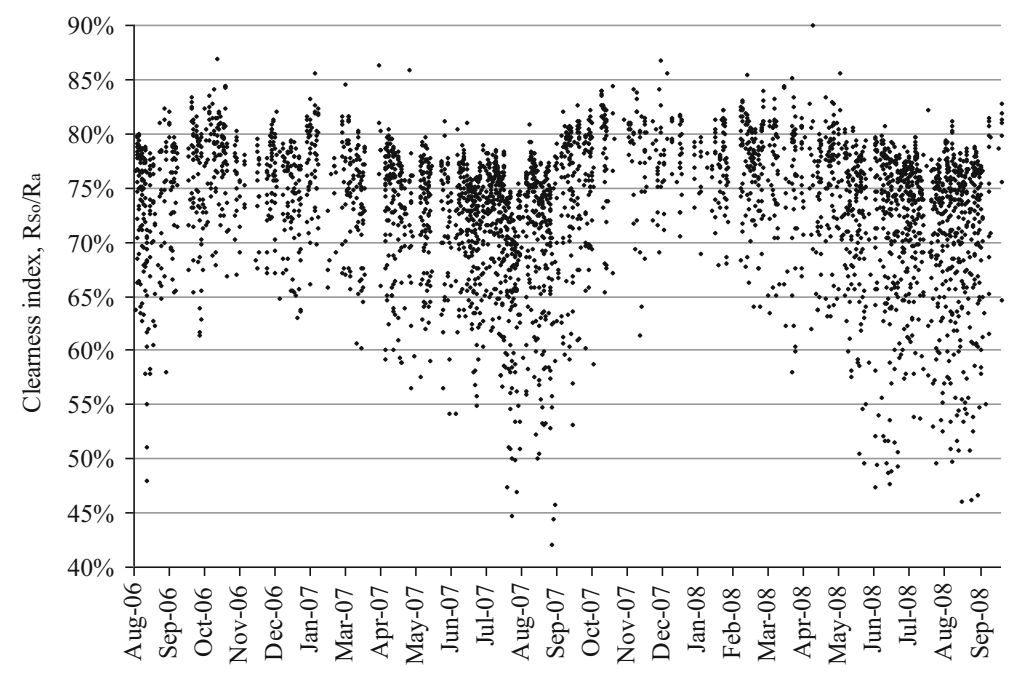

Fig. 2 Hourly values of clearness index under clear sky conditions from 30 August 2006 until 30 September 2008 (data for Amynteo) 


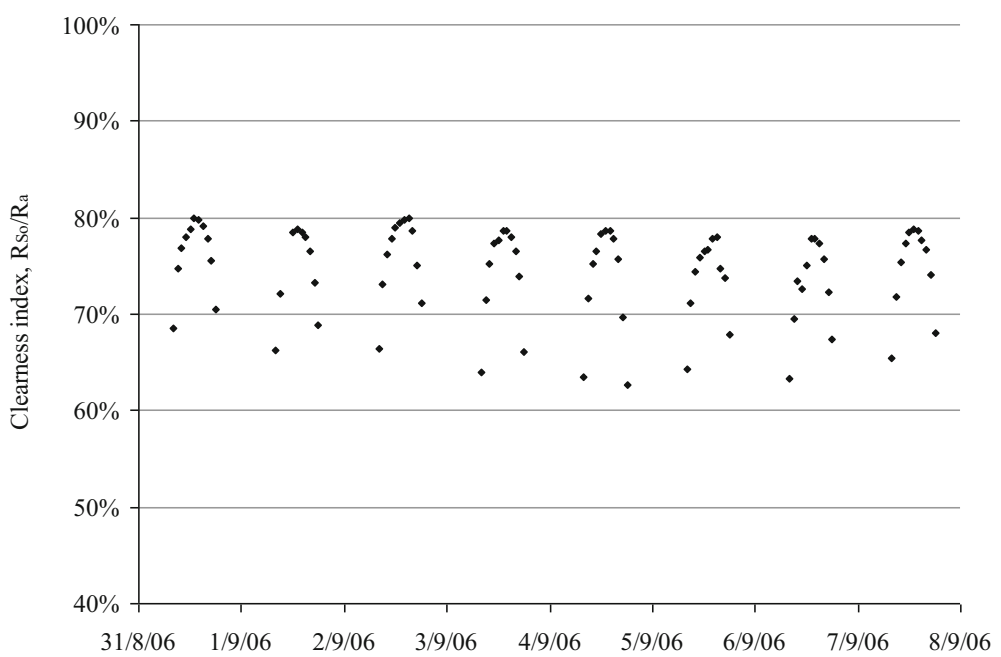

Fig. 3 Hourly values of clearness index for a random period with clear sky conditions (data for Amynteo)

are non-uniform, as there is not any data during night-time and skies are not always clear throughout the day. Lomb-Scargle periodogram of clearness index under clear sky conditions revealed additional frequencies to the two periodicities mentioned above, the aliased frequencies. Aliasing happens because systematically there is missing data due to night-time observations.

A finite number of harmonics can cover the greater part of the time series variation. As a result, to fit the data on a Fourier series, only these harmonics are required. Both methods of spectral analysis showed that two harmonics seem to

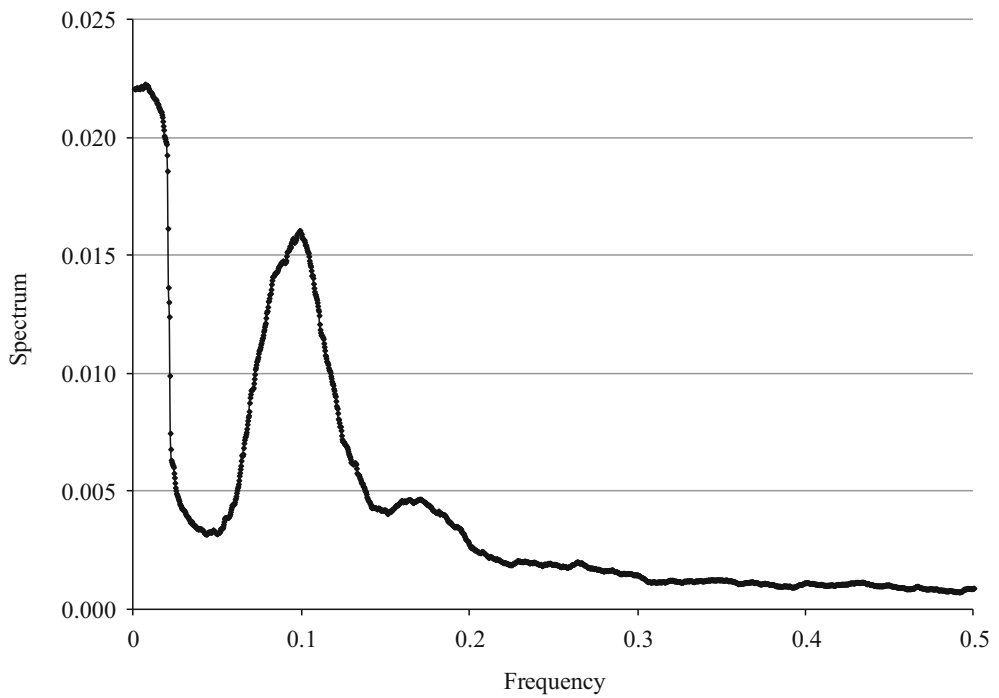

Fig. 4 Smoothed periodogramm of clearness index under clear sky conditions 
adequately cover the clearness index under clear sky conditions; the equation expressing $\mathrm{K}_{\mathrm{To}}$ in the form of a time series is:

$$
K_{T o}(J)=\frac{1}{2} a_{o}+A_{1} \sin \left(\frac{2 \pi}{1} J+\phi_{1}\right)+A_{2} \sin \left(\frac{2 \pi}{365} J+\phi_{2}\right)
$$

where: $\mathrm{K}_{\mathrm{To}}$ is the clearness index under clear sky conditions; and $\mathrm{J}$ is time in days and fraction of the day, e.g., 15 January $12: 00 \mathrm{pm}$ equals to $15.5 ; \phi_{1}, \phi_{2}$ are the phases for the two frequencies; and $\mathrm{A}_{1}, \mathrm{~A}_{2}$ are the amplitudes for the two frequencies.

Equation (5) can be expressed as (Ampas 2010):

$$
K_{T o}(J)=\frac{1}{2} a_{o}+\left[a_{1} \cos \left(\frac{2 \pi}{1} J\right)+b_{1} \sin \left(\frac{2 \pi}{1} J\right)\right]+\left[a_{2} \cos \left(\frac{2 \pi}{365} J\right)+b_{2} \sin \left(\frac{2 \pi}{365} J\right)\right]
$$

Regression analysis can be used on the measured values of the clearness index under clear sky conditions, $K_{T o}$, for time $J$, to estimate the coefficients $a_{0}, a_{1}, a_{2}, b_{1}$, $\mathrm{b}_{2}$. Table 1 provides regression estimates for data drawn from the station in Amynteo.

Thus, the clearness index under clear sky can be estimated by:

$$
K_{T o}=0.60352+0.1846 \sin (2 \pi J-1.9141)+0.0159 \sin \left(\frac{2 \pi}{365} J+0.539\right)
$$

The second term of Eq. (7) expresses the daily periodicity while the third term expresses the annual periodicity. Table 1 provides the respective amplitudes of the two periodicities. The annual width of variation, which is equal to two times the amplitude $(2 * 0.0159)$, is found to be close to the results shown in Fig. 1. Figure 5 shows a diagram of the annual variation on the hourly data of $\mathrm{K}_{\mathrm{To}}$. The daily width of variation, which equals to the amplitude (0.159), is found to be close to the results of the equation that is proposed by ASCE (2005). Figure 6 shows the diagram of the estimated hourly clearness index under clear sky conditions derived for the period of continuous clear sky conditions at the AMS Amynteo, as provided by Eq. (7). Both Figs. 5 and 6 show the fit of the calculated $\mathrm{K}_{\mathrm{To}}$ to the hourly data. $\mathrm{K}_{\mathrm{To}}$ reaches its maximum and minimum values when the sinusoidal functions are equal to 1 or to -1 , respectively, allowing the estimation of the time, $\mathrm{J}$ :

- Maximum value of $\mathrm{K}_{\mathrm{To}}$ during the day takes place at 13:19

- Maximum value of $\mathrm{K}_{\mathrm{To}}$ over the year takes place on the 28th of February

\begin{tabular}{|c|c|c|c|c|}
\hline \multicolumn{3}{|l|}{$\mathrm{R}^{2}$} & \multicolumn{2}{|l|}{0.810882} \\
\hline \multicolumn{3}{|l|}{ RMSE } & \multicolumn{2}{|l|}{0.038094} \\
\hline \multicolumn{3}{|l|}{ Sample } & \multicolumn{2}{|l|}{3587} \\
\hline \multicolumn{3}{|l|}{ Coefficient } & Amplitude & Phase, rad \\
\hline Constant & $\mathrm{a}_{0} / 2$ & 0.60352 & & \\
\hline \multirow[t]{2}{*}{ Daily $(2 \pi J)$} & $b_{1}$ & -0.06216 & 0.1846 & 1.9141 \\
\hline & $a_{1}$ & -0.17387 & & \\
\hline \multirow[t]{2}{*}{ Annually $(2 \pi \mathrm{J} / 365)$} & $\mathrm{b}_{2}$ & 0.01364 & 0.0159 & 0.53899 \\
\hline & $a_{2}$ & 0.00816 & & \\
\hline
\end{tabular}

- Minimum value of $\mathrm{K}_{\mathrm{To}}$ over the year takes place on the 29th of August.

Table 1 Results of optimal fitting of sinusoidal functions to clearness index under clear sky 


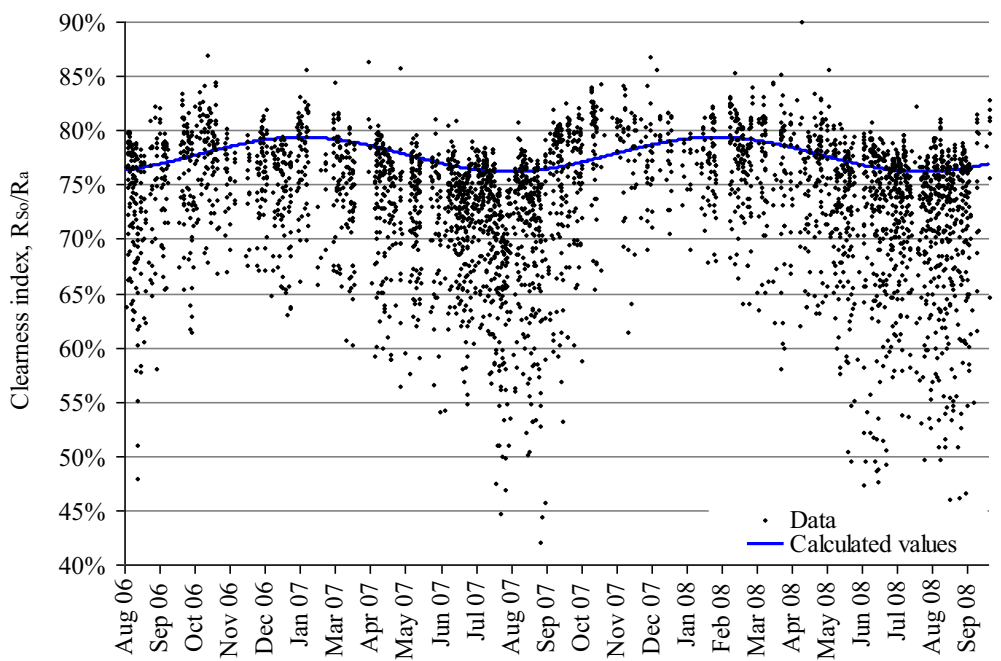

Fig. 5 Diagram of hourly clearness index under clear sky conditions for Amynteo from 30 August 2006 until 30 September 2008 and the calculated values from Eq. (7) for each day at 12:00

\subsection{Overcast}

Benson et al. (1984) mentioned that only direct radiation presents seasonality. So, the Fisher's Kappa test and the Bartlett's Kolmogorov-Smirnov test were used to check the periodicities of time series data of the clearness index under overcast, but both tests failed. Clearness index under overcast does not present periodicities. Figure 7 shows the hourly values of the clearness index under overcast.

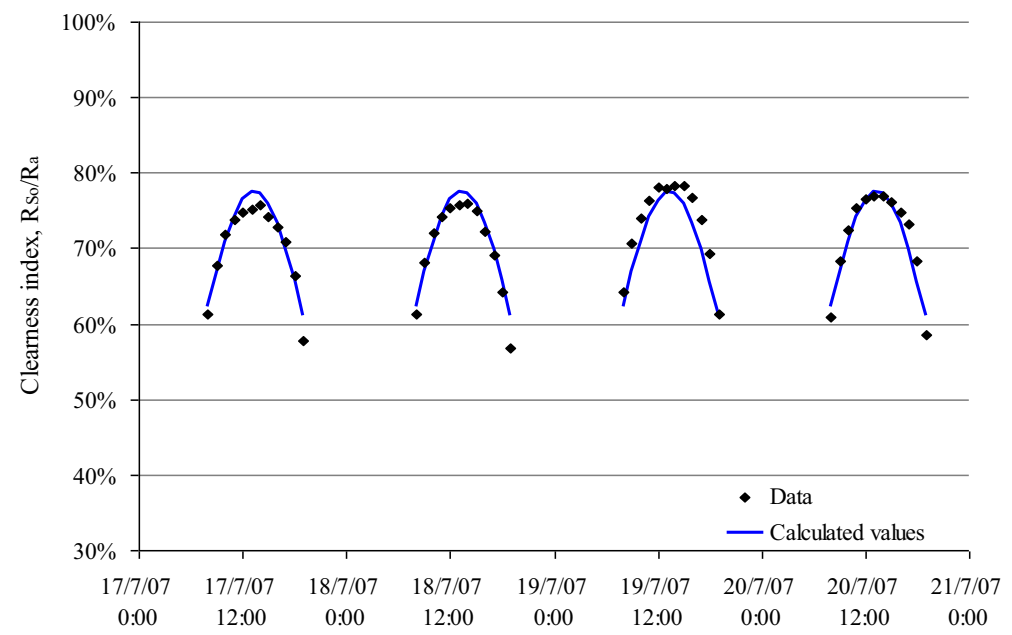

Fig. 6 Diagram of hourly clearness index under clear sky conditions for Amynteo for a period with continuous clear sky conditions 


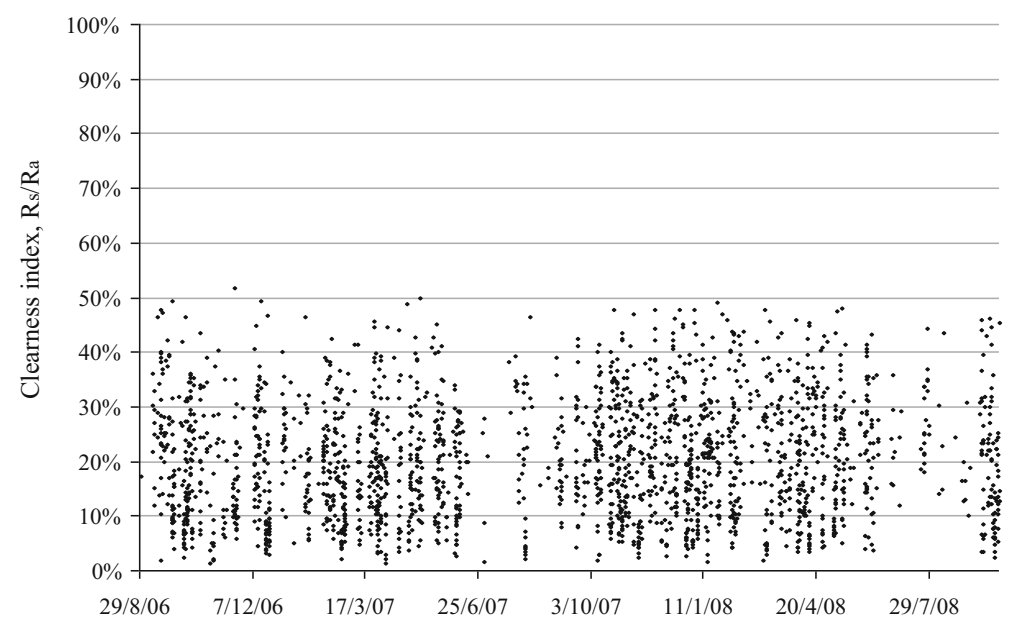

Fig. 7 Diagram of hourly clearness index under overcast for Amynteo from 30 August 2006 until 30 September 2008

Nagaraja Rao et al. (1984) examined the most frequently occurring values of the clearness index under overcast sky. Figure 8 presents the histogram of the frequency of occurrence; the most frequently occurring value, based on the data of the station in Amynteo, is $a_{s}=0.18$. The median of the clearness index under overcast is $19.68 \%$ and the average is $20.3 \%$.

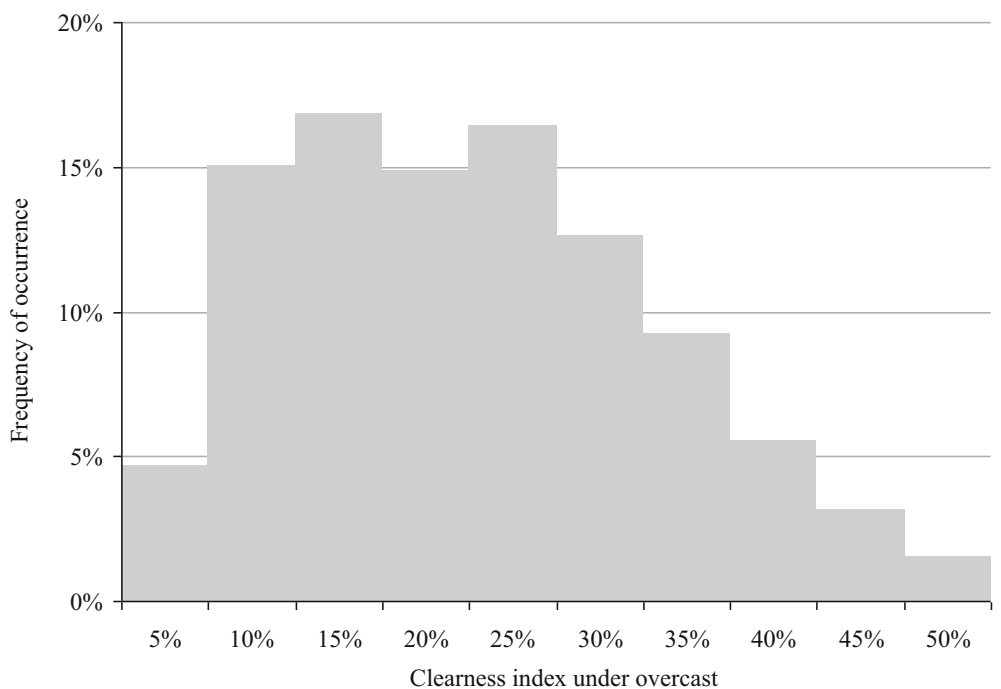

Fig. 8 Histogram of frequency of occurrence hourly clearness index under overcast sky for Fig. 9. Diagram of the hourly clearness index under any condition of cloudiness for the period 30 August 2006 until 30 September 2008 
4.3 Intermediate Percentage of Cloudiness

Accepting the Angström-Prescott equation on the hourly data suggests a linear relationship between the two limit percentages of cloudiness (i.e., clear sky and overcast). Thus, the relation for the clearness index under any percentage of cloudiness is:

$$
\begin{gathered}
a_{s}=0.203 \\
b_{s}=0.4+0.1846 \sin (2 \pi J-1.9141)+0.0159 \sin \left(\frac{2 \pi}{365} J+0.539\right) \\
K_{T}=\left[0.4+0.1846 \sin (2 \pi J-1.9141)+0.0159 \sin \left(\frac{2 \pi}{365} J+0.539\right)\right] \frac{n(h)}{60}+0.203
\end{gathered}
$$

where: $\mathrm{n}(\mathrm{h})$ is the hourly sunshine [min]

Figure 9 shows the measured hourly clearness index under any percentage of cloudiness against the estimated values of this index, as computed by Eq. (8). Figure 10 depicts the hourly clearness index under any percentage of cloudiness against the hourly values of relative sunshine.

Using the estimated hourly clearness index, the daily values of the clearness index can be computed with the following equation:

$$
K_{T(d)}(J)=\frac{\sum_{J}^{J+1} K_{T}(h) R_{a}(h)}{R_{a}(d)}
$$

where: $\mathrm{K}_{\mathrm{T}(\mathrm{d})}$ is the daily clearness index [-]; $\mathrm{J}$ is the day of the year [d]; $\mathrm{K}_{\mathrm{T}}(\mathrm{h})$ is the hourly clearness index calculated from Eq. (8) [-]; $\mathrm{R}_{\mathrm{a}}(\mathrm{h})$ is the hourly extraterrestrial radiation from Eq. (4); and $\mathrm{R}_{\mathrm{a}}(\mathrm{d})$ is the daily extraterrestrial radiation from Eq. (3) $[-]$.

Figure 11 depicts the estimated daily values of the clearness index against the estimated values of clearness index by two different ways, one based on Eq. (9) and

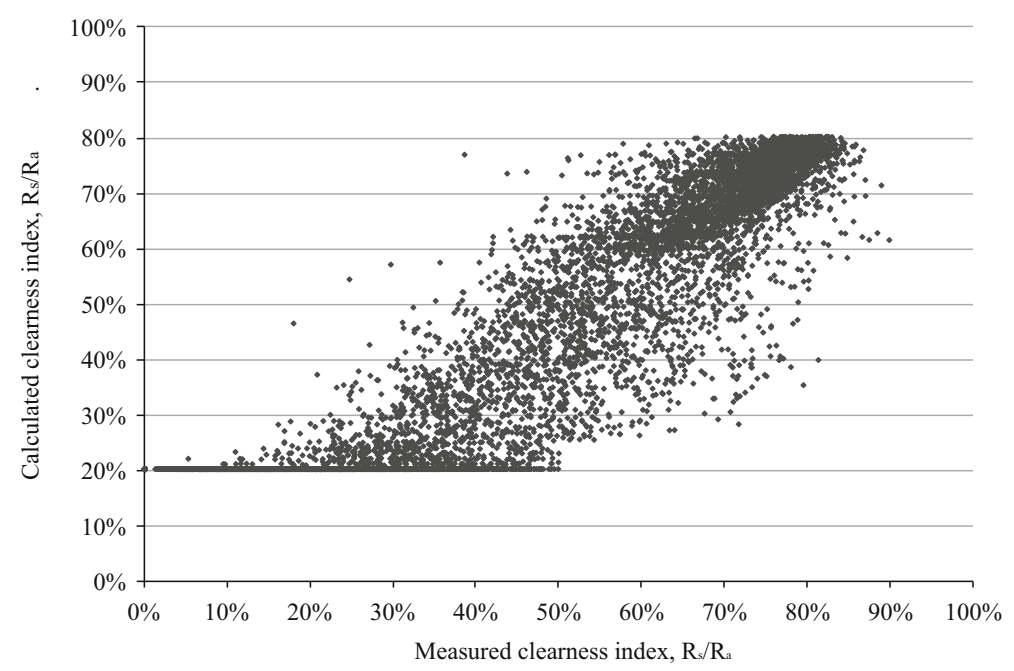

Fig. 9 Diagram of the hourly clearness index under any condition of cloudiness for the period 30 August 2006 until 30 September 2008 


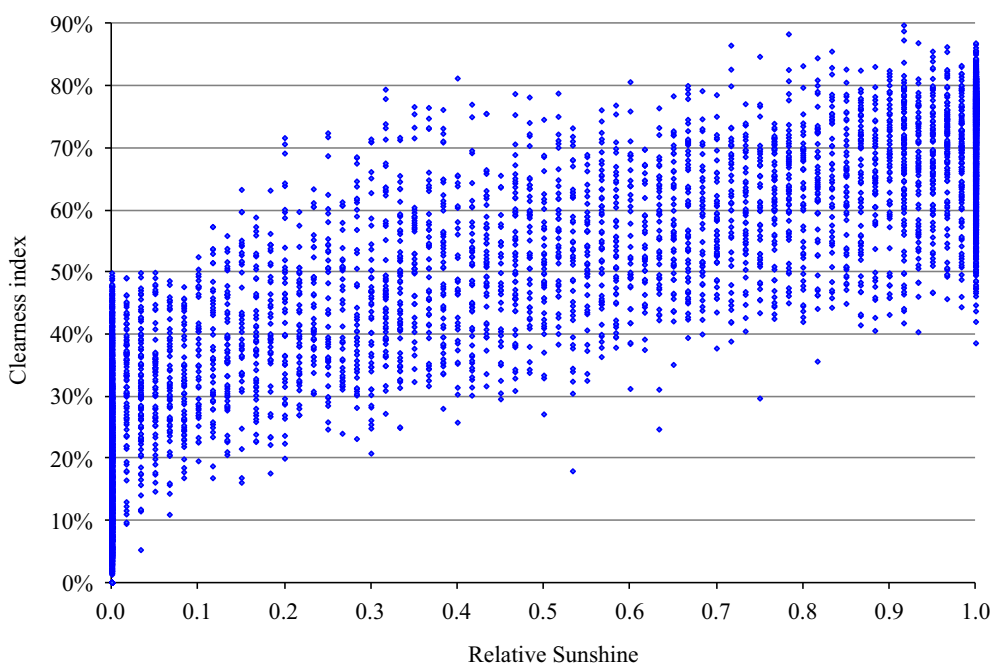

Fig. 10 Hourly clearness index to hourly relative sunshine for Amynteo data from 30 August 2006 until 30 September 2008

another based on a simple regression analysis. Equation (9) calculates the measured daily clearness index more precisely compared to the regression analysis, as elaborated in Table 2.

Figure 11 depicts the data points and the regression line of optimum fit, based on regression analysis results. The coefficient of determination, $\mathrm{R}^{2}$, is higher with the

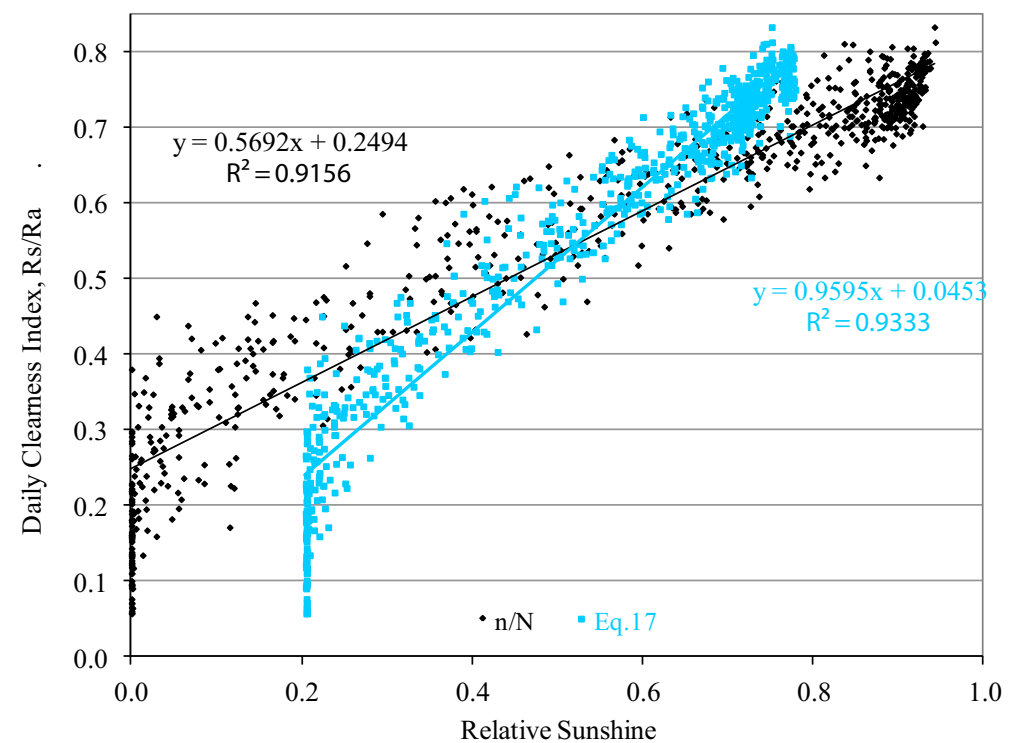

Fig. 11 Measured daily clearness index to relative sunshine. Data are for Amynteo from 30 August 2006 until 30 September 2008 
Table 2 Statistics of the two methods that estimate solar radiation

\begin{tabular}{lll}
\hline & Regression analysis & Equation (9) \\
\hline $\mathrm{R}^{2}$ & 0.9156 & 0.9333 \\
Standard error estimate & 0.060 & 0.053 \\
Mean error estimate & 0.045 & 0.038 \\
\hline
\end{tabular}

new values of adjusted sunshine and the improvement of $\mathrm{R}^{2}$ is higher compared to the adjusted sunshine by Ampas and Baltas (2007).

\section{Summary and Conclusions}

Solar radiation, based on hourly values of sunshine, was estimated. The Angström-Prescott equation was used expressing the relation between solar radiation and sunshine. The factors $a_{s}$ and $b_{\mathrm{s}}$ of this equation have a physical meaning, as $\mathrm{a}_{\mathrm{s}}$ represents overcast conditions and $\mathrm{a}_{\mathrm{s}}+\mathrm{b}_{\mathrm{s}}$ represents conditions in clear sky. Both factors, $a_{s}$ and $b_{s}$, were examined for these discrete conditions. Under clear sky conditions, the clearness index, $\mathrm{R}_{\mathrm{So}} / \mathrm{R}_{\mathrm{a}}$, presented two periodicities. Spectral analysis was performed to investigate these periodicities. In addition, the LombScargle periodogram was used, as the data were unevenly distributed in time. Spectral analysis proved the existence of these two periodicities. Annual periodicity presented a 0.032 width, while the daily periodicity presented an amplitude of 0.184 . The daily periodicity is caused from variation in the travel distance of sunlight in the atmosphere: in Amyndeo at noon (13:19), the distance is smaller, and therefore, the clearness index is higher by $18 \%$. The annual periodicity is caused mainly from the amount of precipitable water, which is more during the summer, as the rise of the temperature contributes to the rise of the absolute humidity. A sinusoidal equation with two harmonics was developed to calculate the clearness index estimated under clear sky conditions. Under overcast conditions, the clearness index, $\mathrm{R}_{\mathrm{s}} /$ $R_{a}$, did not exhibit periodicities. The equation for intermediate percentage of cloudiness stemmed from the sinusoidal equation of the clearness index under clear sky conditions, the mean value of the clearness index under overcast conditions and the linear equation between clearness index and relative sunshine.

The use of the equation developed from the spectral analysis, estimates solar radiation with good results on hourly data, and the best results are obtained when using the equation to estimate daily solar radiation. The equations of the present study may be used for the calculation of solar radiation on an hourly and daily basis with adequate precision. These reliable hourly and daily solar radiation data can be utilized by many models that have been developed for agronomic and hydrological studies. To evaluate phenomena with a large time step, such as climate change, global dimming etc., large time series of specific meteorological parameters, with considerable accuracy, are required. Otherwise, the errors may lead to misleading results.

Equation (6) can be used for the calculation of the hourly Clearness Index under clear sky using hourly data, which is necessary for the calculation of the reference evapotranspiration by the methods FAO24 Penman and FAO56 Penman-Monteith. This method calculates the solar radiation under clear sky, $\mathrm{R}_{\mathrm{So}}$, more accurately than other methods, since the spectral analysis considers the cumulative effect of all individual periodic factors. Application of Eq. (6) shows that the maximum value of the clearness index during the day is at time 13:19 and during the year is on February 28th. The knowledge of the maximum value may be useful in the optimal 
installation of photovoltaic units. The considerable variation of the clearness index during the day probably makes uneconomic the utilization of solar radiation in the morning or afternoon hours from rotating photovoltaic units.

\section{References}

ASCE. Standardization of Reference Evapotranspiration Task Committee (2005) The ASCE standardized reference evapotranspiration equation. Environmental and Water Resources Institute of the American Society of Civil Engineers

Almorox J, Benito M, Hontoria C (2005) Estimation of monthly Angström-Prescott equation coefficients from measured daily data in Toledo, Spain. Renew Energy 30:931-936

Ampas V (2010) Research and estimation of meteorological parameters with direct impact on agriculture. $\mathrm{PhD}$. Thesis. Aristotle University of Thessaloniki

Ampas V, Baltas E (2007) The effect of the daily distribution of the sunshine hours to the total daily solar radiation. Geophys Res Abstr 9:10178

Angström A (1924) Solar and terrestrial radiation. Roy Met Soc 50:121-125

Baltas EA (2007) Spatial distribution of climatic indices in Northern Greece. Meteorol Appl. doi:10.1002/met.7

Benson RB, Paris MV, Sherry JE, Justus CG (1984) Estimation of daily and monthly direct, diffuse and global solar radiation from sunshine duration measurements. Sol Energy 32(4):523-535

Broersen PMT (2008) Spectral analysis of irregularly sampled data with time series models. Open Signal Process J $1: 7-14$

Duffie JA, Beckman WA (2006) Solar Engineering of Thermal Processes, 3rd edn. Wiley, Hoboken, NJ, USA

Glover J, McCulloh JSF (1958) The empirical relation between solar radiation and hours of sunshine. Quart J R Meteorol Soc 84:172

Gopinathan KK (1988) A general formula for computing the coefficients of the correlation connecting global solar radiation to sunshine duration. Sol Energy 41(6):499-502

Hinrichsen K (1994) The Angstrom formula with coefficients having a physical meaning. Sol Energy 52(6):491495

Jin Z, Yezheng W, Gang Y (2005) General formula for estimation of monthly average daily global solar radiation in China. Energy Convers Manag 46:257-268

Kalogirou SA (2009) Solar Energy Engineering: Processes and Systems, ISBN: 978-0-12-374501-9. Academic, Elsevier Science

Klabzuba J, Bures R, Koznarova V (1999) Model calculation of daily sums of global radiation used in growth models. In: Proc. of the Bioclimatology Labour Hours, Zvolen, 121-122

Nagaraja Rao CR, Bradley WA, Lee TY (1984) Some comments on Angstrom type regression models for the estimation of the daily global solar irradiation. Sol Energy 34(1):117-119

Prescott JA (1940) Evaporation from water surface in relation to solar radiation. Trans R Soc Austr 46:14-118

Trnka M, Zalud Z, Eitzinger J, Dubrovsky M (2005) Global solar radiation in central European lowlands estimated by various empirical formulae. Agricult Forest Meteorol 131:54-76

Yang K, Koike T, Baisheng Y (2006) Improving estimation of hourly, daily, and monthly solar radiation by importing global data sets. Agric For Meteorol 137(1-2):43-55

Yin Y, Wu S, Zheng D, Yang Q (2008) Radiation calibration of FAO56 Penman-Monteith model to estimate reference crop evapotranspiration in China. Agric Water Manag 95(1):77-84

Zekai S (2001) Angstrom equation parameter estimation by unrestricted method. Sol Energy 71(2):95-107 